\title{
Rising estimates of terrestrial and global precipitation
}

\author{
Cort J. Willmott ${ }^{1}$, David R. Legates ${ }^{2}$ \\ ${ }^{1}$ Center for Climatic Research, Department of Geography, University of Delaware, Newark, Delaware 19716, USA \\ ${ }^{2}$ Department of Geography, College of Geosciences, University of Oklahoma, Norman, Oklahoma 73019, USA
}

\begin{abstract}
Estimates of long-term average terrestrial and global precipitation that have been made in the 1900 s from raingage observations are examined. Raingage undercatch is documented and evaluated. Bias-producing influences that irregularly-spaced station networks and commonly-used spatial interpolation procedures have on large-scale spatial averages of precipitation also are investigated, primarily using computer-intensive statistics. Interpretation of each of these sources of bias as well as their interaction suggests that long-term average global precipitation has risen even more than the existing record indicates.
\end{abstract}

\section{INTRODUCTION}

Global as well as continental, oceanic and other large-scale precipitation (rain- and snowfall) averages have been estimated traditionally from point measurements (taken by raingages) of the space-time variability in precipitation. Estimates also have been made from remotely-sensed observations (Barrett \& Martin 1981, Arkin 1989) and from general circulation model (GCM) integrations of simulated precipitation fields (Schlesinger 1984). Raingage-based averages, however, continue to be regarded as the most reliable indeed they are the standard to which remotely sensed and GCM estimates are usually compared (Barrett \& Martin 1981, Pitcher et al. 1983). Long-term, largescale precipitation averages made from historical raingage data, in other words, have been accepted by much of the climatological and hydrological communities as unbiased, accurate averages of the true precipitation field.

Nearly all existing raingage-based averages, however, are less-than-reliable estimates of the true averages for 2 major reasons. Raingage catches (measurements) are typically underestimates of actual rainand snowfall at the gage site (Sevruk 1979, 1986), and most large-scale spatial averages of precipitation made from irregularly spaced station data are overestimates of the true station-data averages. The averaging error arises from the inability of historically sparse and uneven station networks (Willmott et al. 1991) to adequately represent the high space-time variability in precipitation (Legates \& Willmott 1990). It also arises from biases inherent in the spatial averaging procedures that have been used. Since the measurement (by raingage) and averaging errors differ in sign, they tend to cancel although, ironically, improvements in the station network tend to damp the spatial averaging error and thus increase the net error (underestimate) to more than $11 \%$ when averaged globally (Legates 1987 , Legates \& Willmott 1990). Recent raingage-derived estimates of large-scale average precipitation (i.e. made from improved station networks), it follows, are underestimates of the true averages.

Within this report, we examine the reasons why most existing estimates of annual average terrestrial $\left(\overline{P_{T}}\right)$ and global $(\bar{P})$ precipitation made from the historical raingage record are unreliable (highly variable), albeit usually underestimates. While many of our arguments also apply to other large-scale precipitation averages, we focus (1) on $\overline{P_{\mathrm{T}}}$ because of its importance to landsurface ecosystems and human endeavors and (2) on $\bar{P}$ because of its importance in establishing the water balance of the Earth. Fresh water from precipitation is simply one of the most essential raw materials for life on Earth. Our emphasis on terrestrial rather than oceanic precipitation also arises because terrestrial precipitation and land-based raingage biases are much better observed and understood. 


\section{RAINGAGE BIAS}

When standard raingage catches of precipitation are compared to measurements of precipitation reaching the ground (usually made with pit gages), the raingage values are smaller. This underestimation has been observed for virtually all nations' standard raingages as well as gages operating at sea (on a ship or buoy). The degree of underestimation, unfortunately, varies with the gage type and siting, the wind field around the gage, wetting losses (water adhering to the walls of the gage and therefore not counted as part of the catch), and evaporation from the gage. A considerable error also usually occurs when the precipitation falls as snow and it is windy. Random errors of various kinds too can amount to as much as $10 \%$ but their expected value is zero and, therefore, they are not considered here. There are, however, means that can be used to remove the systematic gage errors from the station records and obtain relatively unbiased estimates of $\overline{P_{\mathrm{T}}}$ and $\bar{P}$.

Following Sevruk (1979) and Sevruk \& Hamon (1984), for instance, Legates (1987) and Legates \& Willmott (1990) specified a transfer function that can be used to obtain a monthly 'corrected' (bias removed) estimate of actual monthly precipitation $\left(P_{c}\right)$ from a raingage measurement $\left(P_{\mathrm{g}}\right)$. They write

$$
\begin{aligned}
P_{\mathrm{c}}= & (1-R) K_{\mathrm{r}}\left(P_{\mathrm{g}}+\Delta P_{\mathrm{wr}}+\Delta P_{\mathrm{er}}\right) \\
& +R K_{\mathrm{s}}\left(P_{\mathrm{g}}+\Delta P_{\mathrm{ws}}+\Delta P_{\mathrm{es}}\right)
\end{aligned}
$$

where $R=$ the proportion of $P_{\mathrm{g}}$ that falls as snow; $K_{\mathrm{r}}$ and $K_{\mathrm{s}}=$ wind correction coefficients for rain and snow respectively; $\Delta P_{\mathrm{wr}}$ and $\Delta P_{\mathrm{ws}}=$ wetting loss coefficients associated with rain and snow; and $\Delta P_{e r}$ and $\Delta P_{e s}=$ evaporation losses for rain and snow. As $K_{\mathrm{r}} \geq 1, K_{\mathrm{s}} \geq 1$, $0 \leq R \leq 1$ and all dimensioned values in Eq. (1) are positive, it is clear that $P_{c} \geq P_{g}$. It should be noted that the largest source of underestimation is the wind velocity (represented by $K_{\mathrm{r}}$ and $K_{s}$ ) which is exponentially proportional to $\left(P_{\mathrm{c}}-P_{\mathrm{g}}\right)$. To correct shipboard measurements, Eq. (1) could be augmented and respecified to account for the aerodynamic influences of the ship's structure and movement (e.g. velocity relative to the wind velocity, and roll and pitch) as well as for the inadvertent capture of sea spray by the gage.

Legates (1987) and Legates \& Willmott (1990) observed that raingage bias resulted in an undercatch on the order of $11 \%$ when averaged globally. Using over 24000 station records (Fig. 1), they also found that raingage bias exhibits a marked geographic variability. Annually and spatially averaged underestimates, for instance, commonly exceed $40 \%$ in the frequently snow-covered, higher latitudes while they decrease to between 10 and $20 \%$ in the mid-latitudes. Undercatches of less than $5 \%$ are typical in the tropics Percent figures, however, tell an incomplete story since Legates \& Willmott also observed that the average magnitude of the undercatch directly covaries with the average precipitation rate (Fig 2a). It additionally

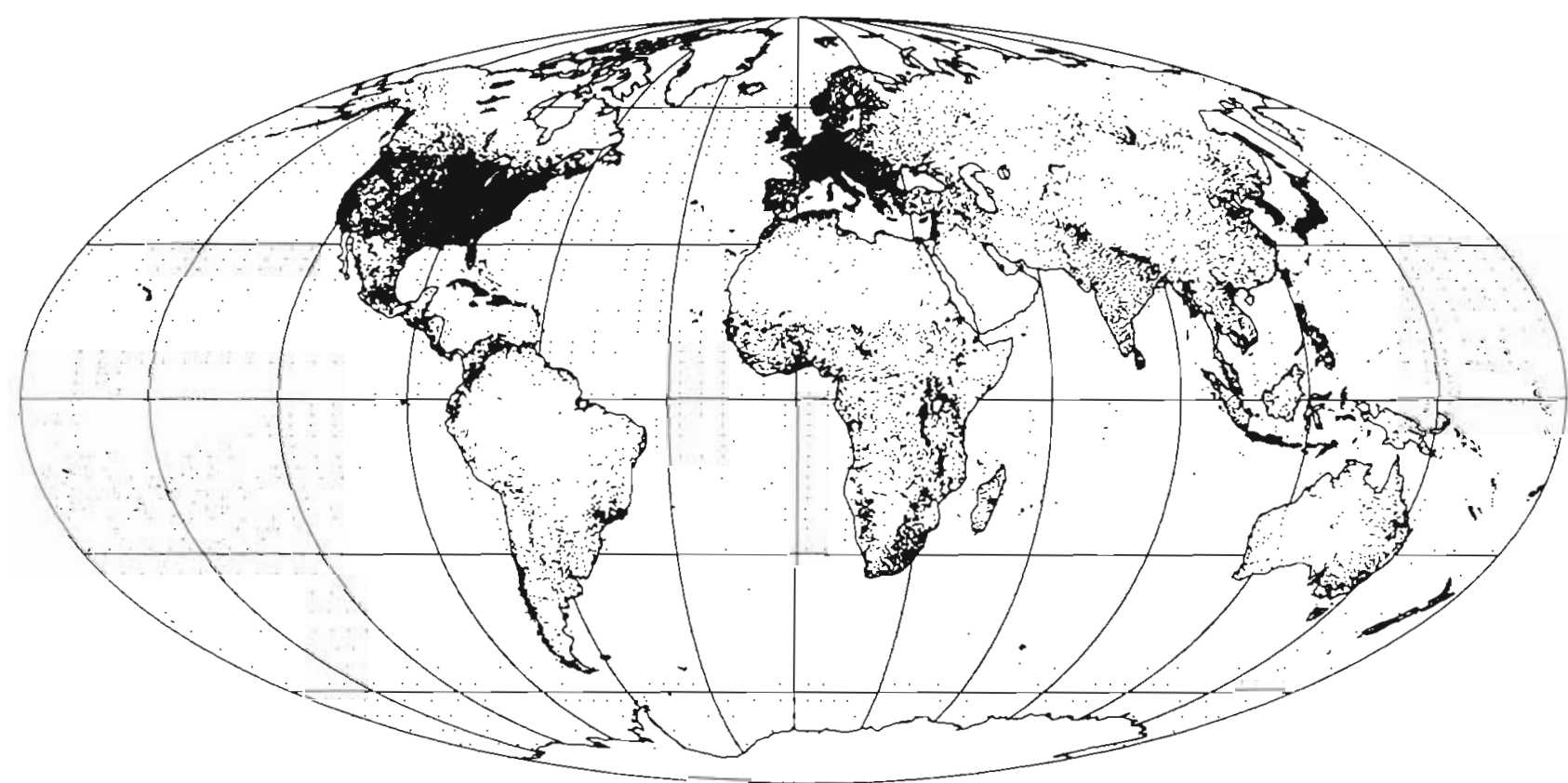

Fig. 1. Locations of 24635 terrestrial. stations and 2223 oceanic grid points at which 12 monthly mean precipitation. averages or estimates were compiled by Legates \& Willmott (1990). An equal-area (Mollweide) projection is used so that station densities among regions can be compared 

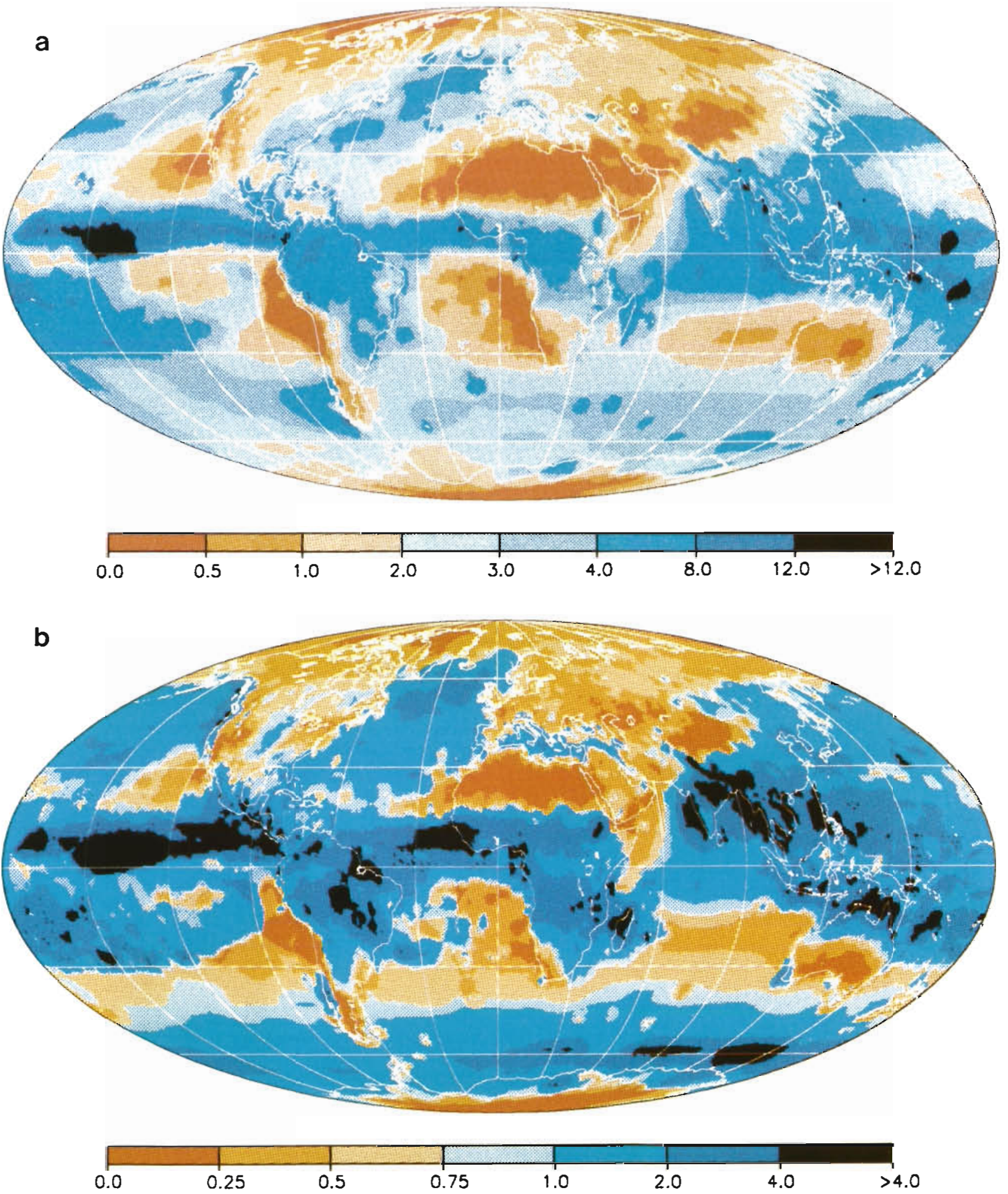

Fig 2. (a) Mean annual precipitation estimated by Legates \& Willmott (1990) from the station network depicted in Fig. 1 Values interpolated from the station network on to a $0.5^{\circ}$ of latitude by $0.5^{\circ}$ of longitude gnd are contoured Isohyets are $05,10,20,3.0$, 4.0. 80 and $12.0 \mathrm{~mm} \mathrm{~d}^{-1}$ Areas having less than $05 \mathrm{~mm} \mathrm{~d} \mathrm{~d}^{-1}$ are red whle areas having more than $12.0 \mathrm{~mm} \mathrm{~d}^{-1}$ are blackened. (b) Temporal standard deviation of mean monthly precipitation estimated by Legates \& Willmott (1990) from the station network depicted in Fig 1 Values interpolated from the station network on to a $0.5^{\circ}$ of latitude by $05^{\circ}$ of longitude grid are contoured Isohyets are $0.25,05,0.75,10,20$ and $40 \mathrm{~mm} \mathrm{~d}^{-1}$ Areas having standard deviations less than $0.25 \mathrm{~mm} \mathrm{~d}^{-1}$ are red while areas with standard deviations greater than $40 \mathrm{~mm} \mathrm{~d}^{-1}$ are blackened 
should be understood that the spatial distribution of precipitation (and associated raingage errors) varies markedly with the seasonal cycle (Fig. 2b).

\section{NETWORK BIAS}

Climatological station networks (for which monthly averages are available) typically have on the order of 10000 to over 20000 station records (cf. Wernstedt 1972, Willmott et al. 1981, Legates \& Willmott 1990) while data bases containing time series of actual monthly totals commonly have fewer than 2500 stations and, before the 1930s, less than 1000 stations. The National Center for Atmospheric Research (NCAR) surface station climatology (Spangler \& Jenne 1984) is representative of the latter. While the number of station records within available data bases has generally increased with time (although, between the early 1970 s and mid-1980s, there was an over $40 \%$ reduction in the number of records available in the NCAR data set), the worldwide networks of available raingage data continue to be spatially uneven and regionally sparse, in spite of the existence of some 120000 operating raingages (Mintz 1981, Baumgartner 1982). Incomplete station networks (historically as well as recently), in other words, constitute a second sampling problem, even within the highest resolution climatological data sets (Fig. 1). It also is common for the station records to span and the climatological averages to represent dissimilar periods of time.

Station densities within most networks are high in many parts of Europe, North America and India but few station records are available for many regions in South America and Africa as well as for mountainous, arid and polar areas. Extreme environments in general are underrepresented. Another problem is that weather stations tend to be located in or near human settlements - in valley bottoms, at break-of-bulk locations or on coasts. Station networks, in other words, typically are biased toward environments that are conducive to human habitation. As these environs are not often dry, large-scale spatial averages made from station data tend to be overestimates. It is actually the synergy between a particular network bias and the way the spatial averaging was accomplished (discussed below) that nets a particular overestimate of the true spatial average.

Oceanic observations made onboard ship additionally are biased in that ships frequent certain routes and not others. A 'fair-weather' bias also exists among the ship data because ships ordinarily circumnavigate the severe weather that is often accompanied by heavy precipitation. Most simple spatial averages made from ship data consequently are underestimates.

\section{SPATIAL AVERAGING BIAS}

Spatial averaging of precipitation estimates usually has been accomplished in 2 steps. Measurements of precipitation (corrected, uncorrected, percentages or frequencies) occurring at irregularly spaced station locations first are used to interpolate (estimate) precipitation at the nodes of a regular grid. Grid point values then can be weighted according to the areas they represent and averaged. Many times the interpolation step has been accomplished 'by eye' from previously interpolated (probably also by eye) isohyetal maps (cf. Baumgartner \& Reichel 1975, Jaeger 1983). Such subjective interpolation cannot be faithfully replicated and can produce sizable errors (Legates 1984). Key elements of the logic behind subjective interpolation, however, have been incorporated into quantitative (sometimes called objective or automated) interpolation and, therefore, many of the points we make about quantitative interpolation (below) also apply to subjective approaches.

Quantitative or automated interpolation methods increasingly have been applied to precipitation data but they too introduce their biases. Automated interpolation of a grid-point estimate of precipitation $\left(\hat{P}_{j}\right)$ usually involves solving

$$
\hat{P}_{j}=\sum_{i=1}^{N_{1}} W_{i} P_{1} / \sum_{i=1}^{N_{i}} W_{i}
$$

where $P_{j}=$ a precipitation value at $\operatorname{Stn} \dot{i}_{;} W_{1}=$ a weight given to $\operatorname{Stn} i_{i}$ and $N_{j}=$ the number of nearby station values used to compute $\hat{P}_{j}$. It is common for $\hat{P}_{j}$ to be constrained so that $\hat{P}_{1}=P_{1}$ when $j \simeq i$ (i.e when the grid point and station location are effectively coincident) although, in some cases, filters have been used that do not require the interpolated surface (represented by the grid-point values) to pass through the station values. A spatial average is then

$$
\bar{P}=\sum_{j=1}^{N} A_{j} \hat{P}_{j} / \sum_{j=1}^{N} A_{i}
$$

where $A_{j}=$ the grid-box area; and $N=$ the number of grid points. Nearly all estimates of $\bar{P}$ or $\overline{P_{T}}$ that have appeared in the literature implicitly or explicitly relied on Eqs. (2) \& (3) to translate irregularly spaced station values into spatial averages. For this reason, we do not consider other interpolation algorithms from among the wide variety that are available (Bennett et al. 1984).

Spatial averages are typically biased due to the inappropriate specification of Eq. (2). The weights in Eq. (2) usually have been selected as an inverse function of the Euclidean distance between grid-point $j$ and $\operatorname{Stn} i$; that is, as measured from a projection of the Earth's spherical surface onto a plane - a map. Problems emanating 
from this approach include: (1) the spherical distances among grid-point $j$ and its $N_{j}$ nearest neighbors are often variably distorted, (2) distance weights (even those based on great circle distances) do not account for uneven arrangements of $N$, data points around gridpoint $j$ and (3) it is impossible to estimate the peak of a 'hiil' or bottom of a 'valley' that may lie beyond the range of the $N_{j}$ data points when $\hat{P}_{j}$ is constrained to equal $P_{1}$ at the station locations. Each problem is discussed in more detail below.

As the distances between Stn $i$ and grid-point $j\left(D_{j j}\right)$ are differentially distorted by different map projections, spatial averages of the same data will differ with the projection used. While this error is not usually significant in local and regional averaging or when the datapoint distribution is dense, projection bias can be considerable in large-scale averaging (Willmott et al. 1985). This is especially true when the station distribution is highly uneven as is the case with the terrestrial precipitation station network. It is difficult, however, to determine whether this error has produced over- or underestimates of any particular large-scale spatial average. This is because key facets of the averaging process (e.g. the spatial arrangement of the weatherstation data, the map projection used, the true spatial distribution of the averaged variable and the interpolation algorithm) are infrequently reported or not invertible.

When stations are clustered or otherwise patterned in their spatial arrangement around a grid point, a value interpolated at the grid point also may be biased in favor of the data-point-rich subregions near the grid point. Consider, for instance, evaluating Eq. (2) with $m$ data points highly clustered at $D_{i j}$ from $j$ and only one data point, also at $D_{j}$ from $j$, on the opposite side of $j$. As $m$ increases,

$$
\hat{P}_{j} \rightarrow \sum_{i=1}^{m} P_{i}^{c} m^{-1}
$$

whereas the convergence should be

$$
\hat{P}_{1} \rightarrow 0.5\left[\left(\sum_{i=1}^{m} p_{i}^{\mathrm{c}} \mathrm{m}^{-1}\right)+p_{i}^{\circ}\right]
$$

Here, $P_{i}^{c}=$ a precipitation value at one of the clustered data points; and $P_{i}^{\circ}=$ the lone precipitation value on the opposite side of the grid point from the data cluster. This bias results, for example, in overestimates of $\hat{P}_{j}$ at grid points located in transition zones between the sparsely gaged deserts and adjacent environs that are wetter and typically have many more raingages per $\mathrm{km}^{2}$.

A third problem (underestimates of local maxima) occurs when $\hat{P}_{j}$ is bounded by the extrema of the $N_{j}$ nearest neighbors. Orographic regimes, for example, often have few stations located in areas where maxima occur (high up on mountain slopes) and therefore Eq. (2) will underestimate at a grid point located in one of these regions. Eq. (2) also is prone to overestimate at a grid point located in a rain shadow, for instance, when no datum lies at the locus of the minimum. Inasmuch as the spatial extent of sparsely gaged wet regions is considerably less than the spatial extent of sparsely gaged dry regions, this extrapolation bias produces overestimates in large-scale spatial averages of $\overline{P_{\mathrm{T}}}$ and therefore $\bar{P}$.

\section{EXPERIMENTAL EVIDENCE}

While the signs of the various network and interpolation biases are known or can be surmised, their magnitudes and their combined or net effects are unknown.
Fig. 3. Estimates of the climatic average rate of global, terrestrial and oceanic precipitation taken from several sources. Each set of symbols $\left(0=\right.$ oceanic $_{1} \square=$ terrestrial and $\Delta=$ global) represents a published finding and is plotted above the year of publication. These averages are based upon different station networks, averaging methods and time periods of record, as well as on different true global distributions of precipitation that occurred during the period of record. Since the latter are unknown and most of the averag. ing procedures and networks are unreported, it is impossible to evaluate the efficacy of each estimate

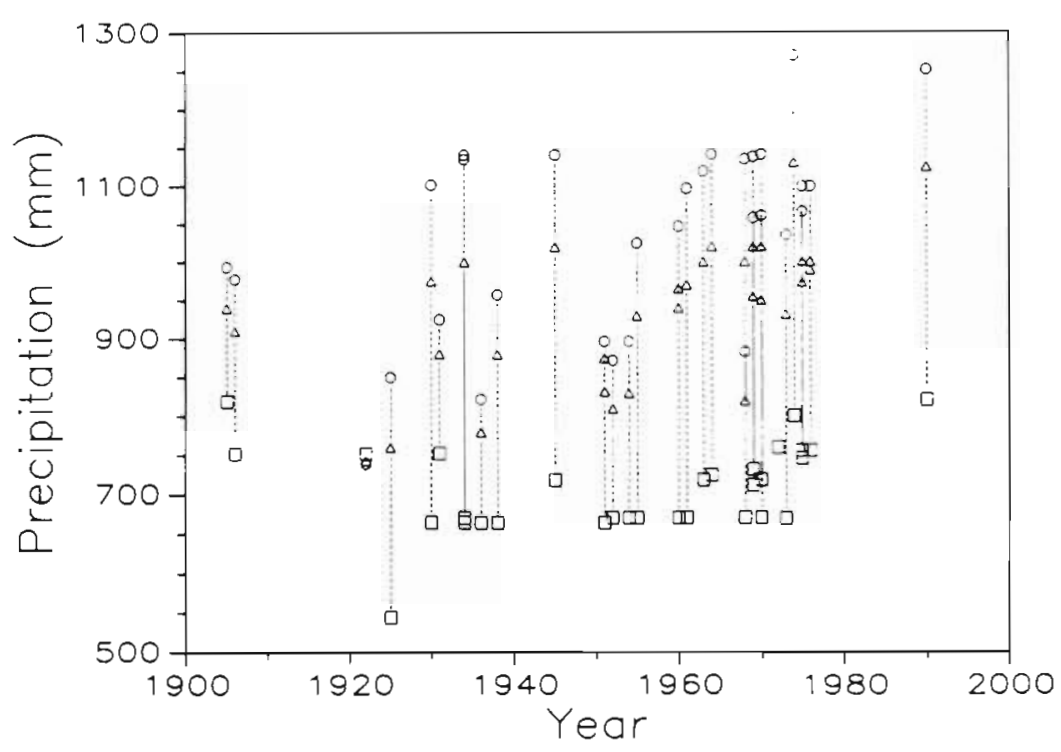




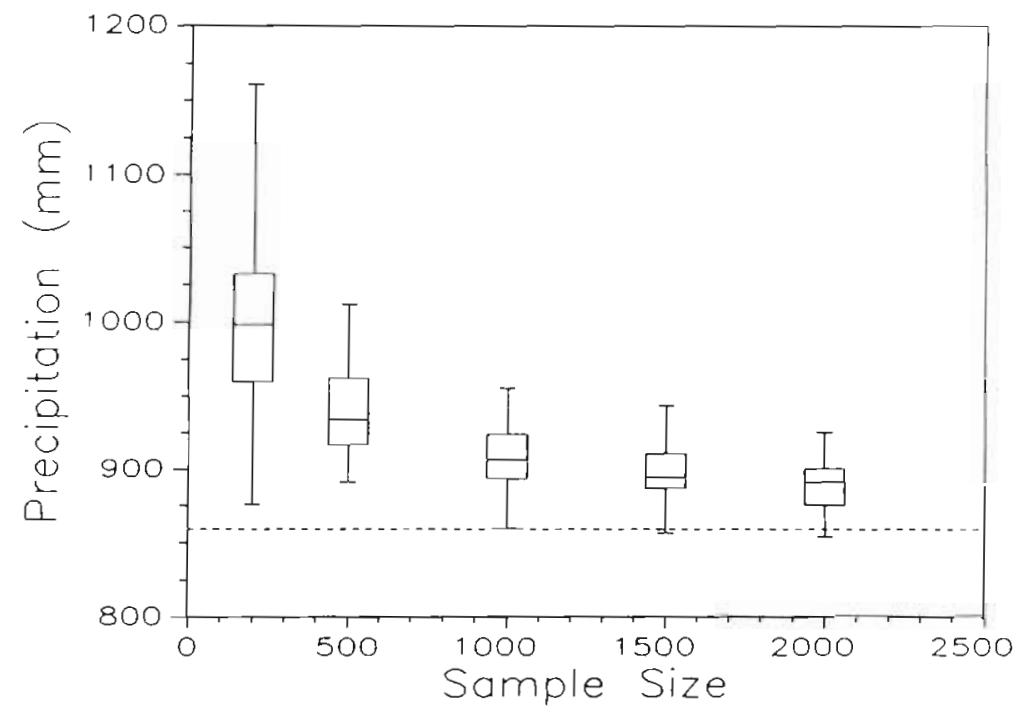

Fig. 4. Box plots of average terrestrial precipitation (not including Antarctica and Greenland). Terrestrial average precipitation was repeatedly estimated from sub-networks of various sizes (numbers of stations) that were randomly sampled from the high-resolution network compiled by Legates \& Willmott (1990) and displayed in Fig. 1. A 'best' estimate of the true terrestrial mean, made from all the station data contained in Legates \& Willmott (1990), is indicated by the dashed line. Samples were selected with replacement and each station had an equal probability of being selected on each trial. Eq. (2) with Shepard's distance-decay function (converted from planar to spherical distance by Willmott et al. 1985) used to obtain the weights $\left(W_{1}\right)$ - was employed to interpolate the grid point estimates

Incomplete reporting of station locations and averaging procedures (mentioned above) used to obtain the historical estimates of $\overline{P_{\mathrm{T}}}$ and $\bar{P}$ (Fig. 3) preclude a posteriori evaluations of combined network and averaging bias. It is possible, however, to construct computerintensive statistical experiments that will yield magnitudes typical of the combined error. Two such experiments were conducted.

In the first experiment, terrestrial average precipitation (excluding Greenland and Antarctica, because of their paucity of station records) was repeatedly estimated from sub-networks that were randomly selected from the high-resolution network compiled by Legates $\&$ Willmott (1990). Stations ( $N_{\mathrm{S}}$ of them) were selected for each sub-network by a simple random sample (with replacement) of all available terrestrial stations (Fig. 1); that is, each terrestrial station and combinations of stations had uniform probabilities of selection. Annual mean gage-corrected precipitation (Fig. 2a) evaluated at those stations then was interpolated to the nodes of a $2^{\circ} \times 2^{\circ}$ spherical grid [using the spherical equivalent of Shepard's (1968) distance weights to solve Eq. (2)] and the spatial integration was made according to Eq. (3). [It should be noted that Bussiéres \& Hogg (1989) have demonstrated the reliability of Shepard's distancebased interpolations of rainfall.] This experiment was repeated 50 times for 5 network sizes $\left(N_{\mathrm{s}}\right)$ in order to establish both the central tendency and variability of estimates of average terrestrial precipitation for different network configurations (Fig. 4).

Sampling from Legates \& Willmott's (1990) highresolution station network was not geographically stratified in order that the sub-networks might mimic the spatial biases present during the historical development of the modern network. It is assumed, in other words, that the general spatial pattern of stations has existed for some time and that the network has merely filled in over time. While this assumption is not strictly true, maps of available stations by year made from the NCAR surface station climatology (not shown) as well as station-location maps from other sources (e.g. Willmott et al. 1981, Diaz et al. 1989) suggest that it is a reasonable proposition.

When the 50 estimates of terrestrial average precipitation for each of the 5 sub-network sizes are represented by 5 box-plots and graphed (Fig. 4), the tendency of sparse networks to overestimate is clear. Overestimates are quite large for sub-networks containing fewer than 1000 stations (e.g. $16 \%$ at $N_{\mathrm{S}}=200$ and $8 \%$ at $N_{\mathrm{s}}=500$ ) but the size of the overestimates asymptotically decreases as $N_{\mathrm{s}}$ increases. Errors on the order of 4 or $5 \%$, nevertheless, are still present when the subnetwork contains as many as 1500 to 2000 stations, Results of this experiment suggest that estimates of terrestrial average raingage-measured precipitation made during the first part of this century are high, perhaps by as much as or more than 10\%. Modern overpredictions from network and averaging bias, however, have probably diminished to less than $5 \%$.

A second and similar experiment was performed using the station distributions for each year (since 1900) contained in the NCAR surface station climatology The NCAR data set was analyzed because it is frequently used by climatologists, and it was compiled with an eye to select the 'best' station records and minimize network bias. It is more representative of evenly-distributed station networks than Legates \& Willmott's data set.

For each year of record, Legates \& Willmott's (1990) high-resolution annual average gage-corrected precipitation field (Fig. 2a) was evaluated at the NCAR station locations for that year, following Willmott et al 
Fig. 5. Time series of (1) average annual gage-corrected terrestrial precipitation (not including Antarctica and Greenland) estimated (interpolated and averaged) from samples of the Legates \& Willmott (1990) high-resolution precipitation field (Fig. 2a) taken at the station locations available each year in the NCAR surface station climatology (solid line) and (2) the number of stations available each year in the NCAR data set (broken line). A best' estimate of the true mean, made from all the station data contained in Legates \& Willmott (1990), is indicated by the horizontal dashed line

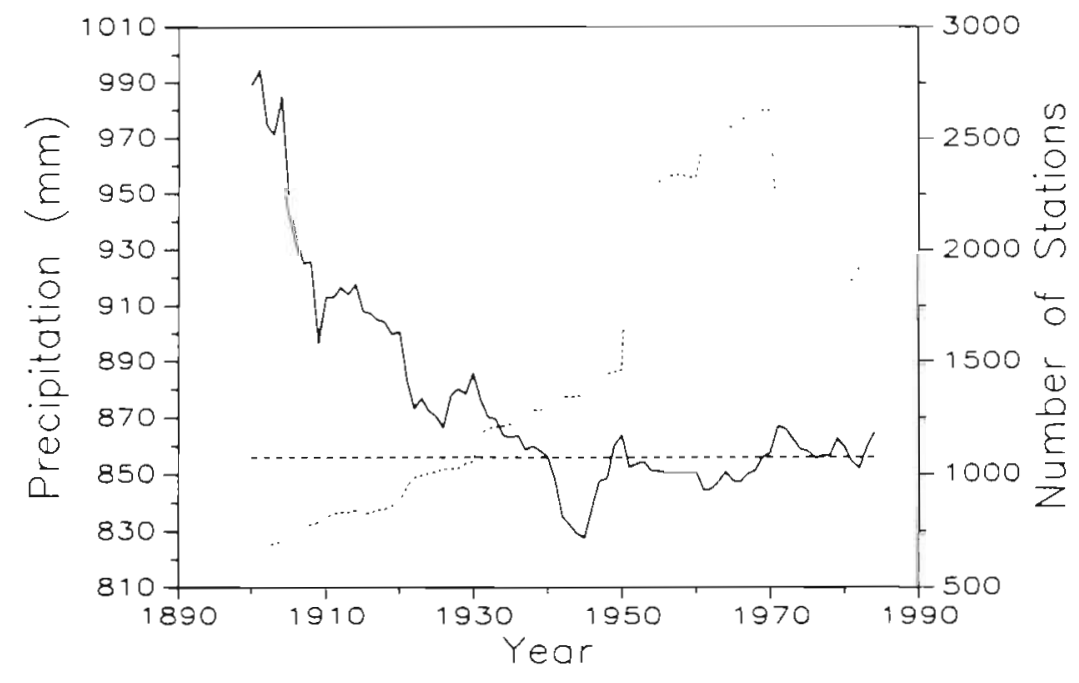

estimates were extremely crude (compared to terrestrial estimates) and low (Legates 1987).

Legates' (1987), and Legates \& Willmott's (1990) evaluation of $\overline{P_{T}}$ and $\bar{P}$, which attempted to circumvent many of the above described sampling and averaging biases as well as raingage bias, produced among the highest empirical estimates of $\overline{P_{\Upsilon}}(820 \mathrm{~mm})$ and $\bar{P}(1123$ $\mathrm{mm}$ ) available (Fig. 3). The only other study that adjusted for raingage bias (Korzun 1974) produced similar estimates of $800 \mathrm{~mm}$ and $1130 \mathrm{~mm}$, respectively. although Korzun used only 1028 stations to represent land areas outside the Soviet Union. It seems likely to us that virtually all other existing estimates (Fig. 3) should be on the order of $10 \%$ higher to account for raingage bias. Several early-in-this-century estimates were based largely on mid-latitude station data (likely having proportionally larger raingage biases) and therefore, should be increased by an additional percent or so. This slight increase was estimated from a comparison of the NCAR-stations experiment described above with a similar experiment based on an uncorrected precipitation field.

Network and spatial averaging bias, when combined, produce overestimates of $\overline{P_{\top}}$ that are inversely proportional (exponentially) to the number of stations (and, of course, their arrangement) in the network. Knowledge of this bias suggests that reductions in existing estimates (Fig. 3) would improve them - after, of course, they have been augmented to account for raingage undercatch. Early-in-this-century estimates of $\overline{P_{\mathrm{T}}}$, in other words, should be reduced, perhaps on the order of $10 \%$, while more recent estimates should probably be reduced by just a few percent. Such adjustments would accentuate the apparent rise in $\overline{P_{\mathrm{T}}}$ and $\bar{P}$ during this century (Fig. 3) and would strengthen the hypothesis that precipitation has been increasing.
Several other researchers also have observed terrestrial $\left(\overline{P_{\mathrm{T}}}\right)$ precipitation have been rising, although estimates of $\overline{P_{O}}$ have risen faster because the early 
increases. Diaz et al. (1989), for instance, reported increases in estimated average land-surface precipitation between 1940 and the mid-1950s, albeit based on a relatively sparse (ca 2000 stations) and uneven network. It also is worth noting that the evolution of the NCAR station network during this period produces a similar-in-appearance but spurious increasing-precipitation signal (Fig. 5).

It is our thesis, in other words, that terrestrial and therefore global precipitation have been increasing over the last several decades. Increasing precipitation might result from increasing available energy at the surface (surface warming). This would provide the energy necessary for higher evapotranspiration rates which, in turn, would have to be balanced (globally) by higher precipitation rates. While our thesis is supported by the terrestrial data, it should be understood that the oceanic data are much less reliable. If oceanic precipitation is increasing as it seems to be (Fig. 3) or is stationary, our thesis is probably correct. If, however, the observed increase in $\overline{P_{O}}$ is spurious, owing to fairweather and other biases, and $\bar{P}_{O}$ is actually declining then our thesis may be false and $\bar{P}$ may be stationary or decreasing. Only in more reliable estimates of $\overline{P_{\mathrm{O}}}$ can the answer be found.

Acknowledgements. Editorial and technical assistance were generously given by Scott Robeson, Kathy Klink and Kenji Matsuura and their help is most appreciated. We also thank Johannes Feddema for collaboration on the analyses of the network influences on spatially-averaged precipitation. Financial support for this research was made available by the National Aeronautics and Space Administration under grants NAG 5-853 and NAGW-1884.

\section{LITERATURE CITED}

Arkin, P. A. (1989). The Global Precipitation Climatology Project. In: Sevruk, B. (ed.) Precipitation measurement. WMO/LAHS/ETH International Workshop on Precipitation Measurement, St. Moritz, Switzerland, p. 491-497

Barrett, E. C., Martin, D. W. (1981). The use of satellite data in rainfall monitoring. Academic Press, New York

Baumgartner, A. (1982). Water balance. In: Eagleson, P. S (ed.) Land surface processes in Atmospheric General Circulation Models. Cambridge University Press, New York, p. $515-538$

Baumgartner, A., Reichel, E. (1975). The world water balance: mean annual global continental, and maritime precipitation, evaporation and runoft. Elsevier, New York

Bennett, R. J., Haining, R. P., Griffith, D. A. (1984). The problem of missing data on spatıal surfaces. Ann. Ass. Am. Geogr. 74: 138-156

Bussiéres, N., Hogg, W (1989). The objectıve analysis of daily rainfall by distance weighting schemes on a mesoscale. grid. Atmosphere-Ocean 27: 521-541

Diaz, H. F., Bradley, R. S., Eischeid, J. K. (1989). Precipitation

Editor: V. Meentemeyer fluctuations over global land areas since the late 1800s. J. Geophys. Res. 94: 1195-1210

Jaeger, L. (1983). Monthly and areal patterns of mean global precipitation. In. Street-Perrott, A., Beran, M., Ratcliffe, R. (eds.) Variations in the global water budget. D. Reidel, Boston, p. 129-140

Kessler, A. (1985). Heat balance climatology, Elsevier, New York (Vol. 1A of the 'World survey of climatology')

Korzun, V I. (Ed.-in-Chief) (1974). World water balance and water resources of the Earth. U.S.S.R. Academy of Sciences, Moscow (Translated into English and published by UNESCO in 1978)

Legates, D. R. (1984). Interpolation of point values from isarithms. Publ. Climatol. 37: 1-66

Legates, D. R. (1987). A climatology of global precipitation Publ. Climatol. 40: 1-84

Legates, D. R., Willmott, C. J. (1990). Mean seasonal and spatial variability in gauge-corrected global precipitation Int. J. Climatol. 10: 111-127

Mintz, Y (1981). A brief review of the present status of global precipitation estimates. In: Atlas, D., Theile, O. W. (eds.) Report of the workshop on precipitation measurements from space. NASA Goddard Space Flight Center, Greenbelt, Maryland, p. 1-4

Pitcher, E. J., Malone, R. C., Ramanathan, V., Blackmon, M L., Puri, K., Bourke, W. (1983). January and July simulations with a Spectral General Circulation Model. J. Atmos. Sci. 40: 580-604

Schlesinger, M. J. (1984). Climate model simulations of $\mathrm{CO}_{2}$ induced climatic change. Adv. Geophys. 26: 141-235

Sevruk, B. (1979). Correction of point precipitation measurement. Versuchsanstalt für Wasserbau, Hydrologie und Glaziologie an der ETH Zürich. Mitteilung Nr. 41 $267-279$

Sevruk, B. (1986). Correction of precipitation measurements: summary report. In: Züricher geographische Schriften, Heft 23 (from the ETH/IAHS/WMO Workshop on the Correction of Precipitation Measurements, Zurich, April 1-3, 1985). Geographisches Institut, Eidgenössische Technische Hochschule, p. 13-23

Sevruk, B., Hamon, W R. (1984). International comparison of national precipitation gauges with a reference pit gauge Instruments and Observing Methods Report No. 17. World Meteorological Organization, Geneva

Shepard, D. (1968). A two-dimensional interpolation function for irregularly-spaced data. In: Proceedings - 1968 ACM National Conference. Brandon/Systems Press, Inc., Princeton, p. 517-524

Spangler, W. M. L., Jenne, R. L. (1984). World monthly surface station climatology. National Center for Atmospheric Research, Boulder, Colorado

Wernstedt, F. L. (1972). World climatic data. Climatic Data Press, Lemont, Pennsylvania

Willmott, C. J., Mather, J. R., Rowe, C. M. (1981). Average monthly and annual surface air temperature and precipitation data for the world. Part I: The eastern hemisphere. Part II: The western hemisphere. Publ. Climatol 34: 1-395, 1-378

Willmott, C. J., Robeson, S. M. Feddema, J. J. (1991). Influence of spatially variable instrument networks on climatic averages. Geophys. Res. Lett. 18: in press

Willmott, C. J., Rowe, C. M., Philpot, W. D. (1985). Small-scale climate maps: a sensitivity analysis of some common assumptions associated with grid-point interpolation and contouring. Am. Cartogr. 12: 5-16 